\title{
The Practice of the Motivational Process in Contemporary Management
}

\author{
Liliya Tukhvatulina $^{1, \mathrm{a}}$, Natalia Cherepanova ${ }^{1}$, Jun Dow ${ }^{1}$, and Nataliya Mirza ${ }^{2}$ \\ ${ }^{1}$ Tomsk Polytechnic University, 634050 Lenin Avenue, 30, Tomsk, Russia \\ ${ }^{2}$ Tomsk State University, 634050 Lenin Avenue, 36, Tomsk, Russia
}

\begin{abstract}
The purpose of this paper is to provide an analysis of the contemporary motivation system at the Russian enterprises. The purpose of the analysis is to find out the main motivators at the enterprises; to highlight the advantages and disadvantages of the existing motivation system and to predict the future development of the motivation system. The given research has been developed by using sociological methods, such as interviews, the analysis of the statistics and simulation method. By analyzing the existing works, the authors have identified the main motivators in connection with the management development periods. Tracing the features of these motivators, the authors have defined the period that corresponds to the incentive system at the Russian enterprises. In practical sphere, the proposed research can be used to develop the motivation system at the Russian enterprises, to make it effective and to predict the potential problems that can appear in the future.
\end{abstract}

\section{Introduction}

Systems and models used in the motivational process of different organizations and countries, is currently the most-discussed area of human resources management. The value of human resource as a primer resource of the enterprise has been highlighted in the theoretical and applied works of scientists of different countries. Thus, the motivational process in Russia is being discussed within the framework of this article. Special attention is given to the identification of motivators that dominate among Russian employees. Using these motivators as a background, the stage of management development is defined. It is our hypotheses that the groups motivators used in the companies can help to identify the relevant stage of management. Applicability of the research is determined by the new forward looking motivation system that can be developed knowing the management development stage and, features of the motivation system of Russian companies. This new system is aimed at preventing organizational problems that are likely to emerge soon.

The main result of the study is the description of the key trends of development of motivation in the nearest future. Our estimate is based on the analysis of motivational systems that existed at different stages of development management as a science.

\section{Materials and methods}

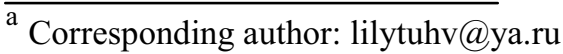

The theoretical background of the given article is based on the post-evolutionary analysis. The post-evolutionary analysis is used to reveal the connection between the motivation peculiarity and the stage of management development. A traditional approach to management introduces three stages of its development: classical, behavioral, and contemporary. Each stage has its own features and an apparent connection with the particular motivation system. We assume that the current status of the Russian management development stage can unmistakably be marked as "classical". This hypothesis finds strong support when current methods of motivation in Russia are analyzed.

The article contains results of applied sociological research. The article reveals the results of motivation analysis of top 100 Tomsk region enterprises [1].

Table 1. Summary statistics of the research.

\begin{tabular}{|l|c|}
\hline \multicolumn{1}{|c|}{ Industrial sector } & $\begin{array}{c}\text { Number of } \\
\text { enterprises }\end{array}$ \\
\hline $\begin{array}{l}\text { Oil and gas, chemical and petrochemical } \\
\text { industry }\end{array}$ & 14 \\
\hline Engineering & 17 \\
\hline Healthcare industry & 2 \\
\hline Nuclear Industry & 1 \\
\hline Timber industry & 9 \\
\hline Energy generating industry & 3 \\
\hline Agriculture & 40 \\
\hline Building and construction work & 14 \\
\hline
\end{tabular}

Source: Self calculation 
Table 1 shows the statistical summary of the enterprises according to their industrial sectors.

The results of motivators' analysis are also used in the article. The motivators' analysis has been carried out by the recruiting agency "Kelly Service Russia" in 20142015.

\section{History of development of the motivational process}

The analysis of various motivational systems is interpreted in connection with three main stages of development of management: classical, human management and contemporary management.

\subsection{The Motivational Process during the Classical Management Stage}

The classical stage of management history came from the beginning of the 20th century. It is well known that it was connected with the name of Frederick W. Taylor. This period of management development includes the concepts of the scientific management and administrative management theory. The basic principles of the classical period were described in the works of $\mathrm{F}$. Taylor [2], H. Ford [3], F and L. Gilbreth [4], H. Fayol [5], etc. For the purpose of this article, the basic principles of motivation of the classical period are listed below.

Principles of motivation of the classical management from the viewpoint of a manager:

1. Reward fairly. Fairness of the reward system is one of the important parts of scientifically based methods of work measurement. It allowed managers to differentiate the wages depending on the level of achievement of workloads or to reward for the performance. Thus, accurate labor equivalents were established and direct relation between compensation and performance quality was monitored.

2. Pay much. It is a famous fact that Mr. Henry Ford increased the wages of workers at his enterprises at the beginning of the 20th century. At other enterprises, adopting the principles of the scientific management, the wages differentiation allowed workers to receive a pay rise from 30 to 100 per cent in addition to their regular level of wages [2].

3. Reward transparently. This is one of the most important principles of compensation within the framework of the scientific management. Frederic W. Taylor developed sets of task works to meet the goal of the transparency of the reward system. Each worker would daily receive the task work to complete throughout the day. It included the following: how the worker knew what should be done; how it should be done; what was the exact amount of time to perform the work. The task work also defined the level of payment the worker would receive. The same goal was achieved via the support of the instruction cards given to workers with the description of the tasks and the task settings.

4. Reward the worker, not the team. The founders of the scientific management developed and supported the idea of individual contribution. Taylor, for example, insisted on rewarding each individual in accordance with his/her individual work result.

5. Reward immediately. Prompt reward became a major motivating factor in the framework of the scientific management. The founders and the followers of the scientific management believed that the reward was to follow the work immediately after its completion. Perhaps this fact is linked with the weekly payroll system still existing in the United States.

Reviewing these factors, we would like to emphasize the obvious point consisting in the fact that scientific management followers saw motivation as direct material incentives. Consequently, the system was focused on the financial element of motivation - wage. This motivation system was clear and transparent for workers: do more for better salary. However, this motivation system would not be complete without revealing existing facts of indirect material stimulation of workers during the scientific management period. It is important to mention these motivational activities introduced by $\mathrm{H}$. Ford. He established the language school for immigrant workers, hospitals where employees and their families were provided with health care. In addition, Henry Ford used a system of cash bonuses for family workers of his enterprises [6]. In any case, the whole system of motivation that existed within the classical period of management was limited only by material incentives and was intended to improve the well-being of workers in an understandable and clear manner.

\subsection{The Motivational Process during the Behavioral Management Movement}

Human relations are a development stage of the management science that became significant in the early 1930 -s of the 20th century. The researchers, who referred to this stage of the management science, "believed that the human aspects of business organizations had been ignored" [7]. Human relations management made the process of motivation somehow more complicated. The main achievement of this period was elimination of the absolute authority of the material incentives. Managers ceased to see the motivation process as a simple, automatic action. Representatives and followers of humanistic management $(\mathrm{H}$. Münsterberg, M.P. Follett, E. Mayo, A. Maslow, etc.) were "... primarily concerned with human psychology, motivation and leadership" [8].

The result of the humanistic management development was a revolution in the core principles of motivation. The basic ideas of motivation during the humanistic period of management can be represented as:

1. Understanding of what the needs of your employees are. In accordance with the recognized theory of A. Maslow [8], motivation was linked with the specific needs of the worker. The level of efforts the worker makes depends on how much s/he wants to meet his/her need. According to Maslow, all human needs are added together into the five-level hierarchy. Each of these levels requires a specific motivator. For example, the first level physiological needs are met by material 
incentives such as salary. And, on contrary, the needs for recognition are intangible. The only problem for the managers is to identify the levels of needs their employees are currently at.

2. Offering something significant and stimulating to your employees. Humanistic theory of management pointed out that money was not the only motivator for workers. At a certain stage, workers start to appreciate and value the intangible motivators. Therefore, the company should not introduce only material rewards like wages and bonuses, but also bring in non-material motivators such as recognition or praise.

3. Allowing employees to motivate themselves. The theory of humanistic management assumed the occasions of self-motivated employees. To illustrate this statement, it is worth viewing the theory by $\mathrm{D}$. McClelland. McClelland considered three types of needs: the need for achievement, the need for power and the need for affiliation [9]. Each need is a combination of individual preferred needs and factors of environmental influence. Therefore, these needs can be satisfied by occupying a certain position in organization. For instance, the employee's need for power could be met by obtaining a responsible position within the organization. Thus, it is clear that in some cases employees can motivate themselves. And the task for the manager is to cease creating obstacles to such endeavour.

4. Being aware that motivators/incentives are constantly changing and accumulating. Humanistic theory of management revealed the complex nature of motivation. This complexity becomes apparent from two viewpoints: motivators are constantly changing and motivators are being accumulated. Changing of the nature of motivators can be seen in Maslow's hierarchy. When the employee meets one need, s/he immediately steps up to the new level of needs of the higher order. Moreover, needs are accumulated, owing to a permanent change of the motivation nature. When an employee has satisfied one need and s/he moves further, it does not mean that the need of the lower level is no longer important. For example, as soon as an employee's need for safety is met (for example, $s /$ he is offered comprehensive social insurance), the need, for example, for socialization can arise. A new need means a new motivation level, and, in this case, teamwork and communication with other group members become the motivator for this employee. However, if the manager cancels the insurance (previous incentive), the employee will return to the level of security needs.

During the humanistic management stage, motivation became ultimately more complex for business leaders. Motivation was no longer seen as wages per se. Intangible incentives were becoming more and more important for both: managers and employees. For employees motivation ceased to be clear and understandable. The rule of the classical management: "work more for better money" was no longer applicable. Some of the managers started applying simplified ideas of the humanistic management. For example, they started replacing material incentives with intangible ones or offering employees non-relevant motivators. Nonetheless, one of the greatest achievements of the humanistic management was that employees were no longer viewed as a part of a perfect mechanism, but as an influential resource for the organization.

\subsection{The Motivational Process in Contemporary Management Movement}

Contemporary management is represented with a complex of integrated ideas, theories and approaches [10]. A key role in the development of contemporary management belongs to the general scientific approaches in the multidisciplinary fields: the process approach [11], the contingency approach [12, 13], the system approach [14]. It is apparent, that the general scientific approaches listed above are not the latest in terms of chronology. However, it is clear that new ideas of management are formed on the basis of these approaches. In the motivational process, for example, there are new kinds of motivators that come into existence. Some of the novel motivators of contemporary management are listed below:

1. Communication. Great attention is paid to the process of communication in the contemporary management system. A system approach considers an enterprise as a system, which consists of separate elements. The connection between elements becomes equally important for their well-coordinated work. Therefore, ultimately, the process of communication itself becomes a motivator for workers. Motivational functions of communication are characterized by their different aspects (internal/external, horizontal/vertical, formal/informal). The degree of the employee's involvement in these communication networks plays an important part as well. Employees want to know and understand how the objectives and the strategy of the enterprise are determined and which of the results are pursued by the administration.

2. Corporate social responsibility (CSR). The efficiency of contemporary management suggests participation of employees of all levels in enterprise administrating. Managers encourage employees to participate in the changing of the management process [15] actively. In terms of participation of each employee in the management of the enterprise, their activity is supposed to comply with specific rules of conduct. These standards of conduct must be accepted and absorbed by workers, as well as transmitted via various communication channels [16]. The company sees its employees as major stakeholders for CSR programs. The programs that are in-house oriented aim at additional motivation activities for personnel $[16,17]$.

3. A management style. Contemporary theories of management have changed the traditional view of enterprise management. Currently, a management style becomes a new type of motivators for many employees. In the traditional management approach, a manager was not seen as a part of the work team. Manager used to serve as a "border person" between top-management and employees. Currently, it is absolutely necessary for an effective manager to become a leader. The leader is an essential member of the team. S/He shares interests, culture and values of the group. A leader, above all, is 
involved in the process of performing the work assignments. Leaders are not inspired by orders. In contemporary management, the fact that managers do all things right and leaders do the right thing [18] is true. In such circumstances, employees are free to choose the enterprises, where administrators do behave like leaders rather than managers.

4. Creativity of motivators. Currently companies develop and apply unique motivation systems. Creative human resources policies become motivators for employees. One of the companies famous for its unusual personnel policy is Google. The Google Company has a position of a "Good Fellow (which nobody can deny)" in its structure. He and the team, originated at Google, are working on solution of the problem of unhappiness and its ultimate destination - war [19].

\section{The Motivational Process in Contemporary Russian Management}

Each stage of management has its own specific motivators. The classical period was concerned about material motivators such as salaries. A humanistic period introduced both tangible and intangible motivators. The modern period is focused on the intangible motivators. If we look at the structure of motivators currently used in Russia, we can indicate that the motivational system in Russia has features of the classical period of management development. Examining this motivation system closely, we can indicate that workers are oriented on tangible (material, financial) motivators. This hypothesis has found the support in the results of the study performed by the recruiting company "Kelly Services". Nearly 5939 people participated in the study in 2014, and 5490 people participated in the study of 2015, respectively. The workers were interviewed in Moscow, St. Petersburg and other regions of Russia. The study revealed the top 5 of the most important work motivators in Russia (Table 2).

Table 2. Top 5 of the personnel motivators in Russia

\begin{tabular}{|l|c|c|c|}
\hline \multicolumn{1}{|c|}{ Motivators } & $\begin{array}{c}2014, \text { per } \\
\text { cent }\end{array}$ & $\begin{array}{c}2015, \text { per } \\
\text { cent }\end{array}$ & Variation \\
\hline Wage & 77 & 72 & -5 \\
\hline Official employment & 38 & 38 & - \\
\hline Career & 37 & 35 & -2 \\
\hline $\begin{array}{l}\text { Quality of the working } \\
\text { tasks }\end{array}$ & 37 & 32 & -5 \\
\hline Organizational culture & 30 & 30 & - \\
\hline
\end{tabular}

Source: Annual survey by "Kelly Services" [20, 21]

The results in Table 2 show that wages has the highest importance for Russian workers. During the interview, the employees responded that they could easily tolerate routine work, regular revisions and lack of career opportunities if they were offered meaningful wages. Almost 71 per cent of employees (in 2014 and 2015 study) pointed out that an increase in the wages can make them stay in a current position.

In addition, it has become apparent that intangible motivation has almost no importance for employees of
Russian companies. However, besides having a decent salary, the workers identified public recognition as a supplementary motivator. Eventually 13 per cent of the participants indicated that intangible motivators have no importance for them at all. More than a half of the interviewed workers (nearly 53 per cent) have an impression that managers do not use intangible motivators properly.

Thus, Russian employees see a salary as a major motivator. Intangible motivators are not apparent for employees and are not attractive to them. Russian companies, in return, have nothing to offer to their personnel. More than 100 leading enterprises of Tomsk region have been selected for the review. The enterprises belonged to different sectors of the economy: the enterprises of gas and oil complex; chemical and petrochemical industry; the engineering enterprises; the enterprise of nuclear industry; the enterprises of timber industry complex; the enterprise of construction industry; the enterprise of power engineering and communications, and the enterprise of the agricultural sector.

The results of the analysis are represented below.

- 54.16 per cent of the companies do not set longterm human resource goals. They do not plan to develop the motivational system in the nearest future.

- 29.6 per cent of the companies offer only a direct reward system to their employees. The most common incentives among employers are: direct salary, bonus, payouts on the occasion of the anniversary or other significant events

- 45.8 per cent offer of the enterprises, in addition to direct payments, offer full or partial reimbursement of vacation or holiday cost, etc.

- 20.8 per cent of the companies use elements of intangible motivation. For example, employees receive industry achievement rewards; the best employee reward, honor roll rewards. In addition, the enterprises offer cultural events or introduce uniforms as an intangible incentive

- 4.1 per cent of the enterprises use solely intangible motivation.

Most comprehensively the motivation is presented at the enterprises of gas and oil industry, chemical and petrochemical industries, as well as at the enterprise of nuclear industry. Virtually, no coherent system of motivation could be found on the enterprises of machinebuilding industry and agriculture industry.

Thus, Russian managers are mostly focused on direct and indirect payments incentives. However, a rapid change is likely to be anticipated in the nearest future. It is necessary for managers to establish a system of intangible incentives. Adherence to the principles of the classical, humanistic management brings in intangible aspects of the motivational process in the enterprise environment. This trend is already noticeable according to Table 2, where the recession of material factors is noticeable.

\section{Conclusion}


Currently, Russian companies offer salaries and guaranteed social security policies to their staff as the major motivators. We proved that this system used to have a full analogue during the classical management movement in the US. Basically, H. Ford and F.W. Taylor offered their employees the very same motivators, and in the long run, intangible motivators were not considered as effective ones. This view on understanding of motivation is equally shared by the employees of Russian enterprises.

However, further development of management brings an up-to-date humanistic approach. In the course of time, intangible incentives will become an important aspect of motivation for Russian employees. In order to initiate this process, Russian enterprises should start establishing intangible-based motivation systems.

\section{References}

1. Annual list of significant enterprises of Tomsk region, 2014, Access mode: http://archive.mid.ru// bdomp/ns-dipecon.nsf/1517c199eb1da84743256a $\underline{420049024 \mathrm{a} / 40 \mathrm{e} 875 \mathrm{fa} 0118 \mathrm{f} 9 \mathrm{bd} 43256 \mathrm{c} 870023 \mathrm{a} 830}$ (Access date: 19.09.2015) (2015)

2. F.W. Taylor, The Principles of Scientific Management (Harper and Brothers, New York, 1911)

3. H. Ford, S. Crowther, My Life and Work. (Doubleday, Harvard, 1922)

4. F.B. Gilbreth, L.M. Gilbreth, Applied Motion Study,। (Sturgis and Walton, New York, 1917)

5. H. Fayol, General and Industrial Management, Pitman and Sons, London (1949)

6. P. Patton, Made in U.S.A.: The Secret Histories of the Things That Made America (Grove Pr., 1992)

7. W. Pindur, S.E. Rogers, Pan Suk Kim, Journal of Management History, 1, 59-77 (1995)

8. A.A Maslow, Psychological Review, 50, 370-396 (1943)

9. D. McClelland, The Achieving Society (Van Nostrand, NJ: Princeton, 1961)

10. N.V. Cherepanova, L.R. Tukhvatulina, A.V. Eremina The 26th International Business Information Management Association Conference: Proceedings (IBIMA, Madrid: IBIMA, 2227-2235, 2015)

11. H. Koontz, Journal of the Academy of Management, 12, 174-188 (1961)

12. P.R. Lawrence, J.W. Lorsch, Developing Organization: Diagnosis and Action (AddisonWesley, Reading, MA, 1696)

13. E. Schein, Organization Psychology (NJ: PrenticeHall, Englewood Cliffs, 1972)

14. L. von Bertalanffy, General System Theory (New York: George Braziller, 1969)

15. W. E. Deming, Out of the crisis (Cambridge, Mass.: MIT Press ,2000)

16. N. Cherepanova, L. Tukhvatulina, A. Eremina, Procedia - Social and Behavioral Sciences, 166, 583-588 (2015)

17. A.V. Khaperskaya, K.A. Bannova, S. Z. Musina, Second International Conference on Economics and
Management (ICEM2015): Conference Proceedings (China, Lancaster: DEStech Publications Inc., 390394, 2015)

18. M. Stewart, Management Myth. Why the Experts Keep Getting it Wrong (New York, W.W. Norton \& Company, 2009)

19. J. Bort, This Google engineer's title is 'Jolly Good Fellow' and he is solving unhappiness and war. Access mode: http://www.businessinsider.com /google-jolly-good-fellow-chade-meng-tan-2015-9 (Access date: 19.09.2015) (2015).

20. Kelly Services Russia, Personnel motivation: annual survey Access mode: http://www.kellyservices.ru/ $\underline{\text { RU/Business-Services/Business-Resource-Center/ }}$ Workforce-Trends/KGWI-4-2014/?hid=CA\#. VNZgj_msXz4 (Access date: 08.02.2015) (2014)

21. Kelly Services Russia, Personnel motivation: annual survey Access mode: http://www.kellyservices.ru/ ru/business-services/business-resource-center/work force-trends/motivation-2015/?hid=ca\#. Vgmo9Pntmko (Access date: 18.09.2015) (2015) 